\title{
ETHOS AMAZÔNIDA: A POIÉSIS DIALÓGICA IDENTITÁRIA RIBEIRINHA
}

\author{
Larissa da Silva Sicsú ${ }^{1}$ \\ Pedro Rapozo ${ }^{2}$ \\ Eneila Almeida dos Santos ${ }^{3}$
}

\begin{abstract}
RESUMO
Ser amazônida, ser caboclo, ribeirinho, indígena, ser gente. Está inserido numa vasta área, cortada por rios colossais de esplêndida biodiversidade. Diante de um universo tão amplo, reflete-se acerca de como este ser, por meio de suas essências identitárias, dialoga com sua vivência social e ao mesmo tempo com o cenário natural em que se encontra. Comunidades que perfazem sua história em meio a constantes transformações da contemporaneidade, ao mesmo tempo que são moradores das margens dos rios, adaptados às mudanças sazonais do território amazônico. Neste sentido, enaltece-se a importância do presente artigo, enfatizando-se o contexto amazônico ribeirinho e o indivíduo inserido neste, abordando-se, então, que características identitárias ele possui e de que forma essas nuances o descrevem enquanto ser amazônida. Assim, na primeira sessão deste artigo, embasado em um levantamento bibliográfico, enfatiza-se sobre os conceitos de identidade, destacando importantes escritores dessa área de conhecimento. Na segunda parte, desvela-se a relação desses conceitos com o ethos ribeirinho, partindo-se de uma visão multifacetada, transcreve-se a poiésis do ser amazônico nas suas práxis diárias, de como ele mesmo se vê, trazendo para o protagonismo o sujeito caboclo enquanto ser primordial na sua formação social e de suas vertentes identitárias.
\end{abstract}

Palavras-Chave: Identidade. Ribeirinho. Amazônida.

\section{AMAZON ETHOS: THE RIBEIRINHA IDENTITY DIALOGICAL POIESIS}

\begin{abstract}
Being an Amazonida, being a caboclo, riverside, indigenous, being people. Being inserted in a vast area, crossed by colossal rivers of splendid biodiversity. Before such a wide universe, it reflects on how this being, through its identity essences, dialogues with its social experience and at the same time with the natural scenario in which it is included. Communities that make up their history in the midst of constant transformations of contemporary times, at the same time that they live by the river, adapted to the seasonal changes of the Amazonian territory. In this sense, the importance of the present article is highlighted, it emphasizes the Amazonian riverside context and the individual inserted in this midst, then addressing what identity characteristics it has and how these nuances describe it like an Amazonida. Thus, in the first session of this article, based on a bibliographic survey, it emphasizes the concepts of identity, highlighting important writers of this area of knowledge. In the second part, the relationship of these concepts with the riverside ethos is unveiled, starting from a multifaceted vision, transcribing the poiesis of the Amazonian being in his daily praxis, of how it sees itself, bringing caboclo subject as protagonist, as primordial being in its social formation and its identity strands.
\end{abstract}

Keywords: Identity. Riverside. Amazonida.

Data de submissão: 17.05 .2021

\footnotetext{
1 Mestranda do Programa de Pós-Graduação em Ciências Humanas. Especialista em Dança Educação pela Universidade do Estado do Amazonas, UEA. Licenciada em Dança pela Escola Superior de Artes e Turismo da Universidade do Estado do Amazonas. Bacharel em Fisioterapia pela Universidade Nilton Lins. CV: http://lattes.cnpq.br/7782767513551936. E-mail: sicsularissa@gmail.com.

2 Professor do Programa de Pós-Graduação Interdisciplinar em Ciências Humanas - PPGI.CH/UEA, CV: http://lattes.cnpq.br/2679908172389276. E-mail: phrapozo@uea.edu.br.

${ }^{3}$ Professora doutora do Programa de Pós-Graduação Interdisciplinar em Ciências Humanas Universidade do Estado do Amazonas. E-mail: eadsantos@uea.edu.br.
} 
Data de aprovação: 19.11 .2021

\section{INTRODUÇÃO}

Na formação do ser humano, seja enquanto indivíduo ou em sociedade, atuam em sua vivência elementos que se tornam pilares para sua existência e um dos mais primordiais é a ideia de identidade. Torna-se instigante refletir que o mesmo possui características diversas que são influenciadas pelo meio em que se desenvolve. Para o indivíduo oriundo de espaços tão complexos e únicos, como pode ser assim citado a Amazônia, está o homem nativo, imbricado neste amplo universo. Ser amazônida, ser caboclo, ribeirinho, indígena, ser gente. Tantas nomenclaturas, tantos povos ao mesmo tempo sendo apenas um, sendo vertente, inserido numa vasta área, cortados por rios colossais, de esplêndida biodiversidade. Moradores possuidores de saberes e sujeitos de diversas facetas culturais, e por que não ressaltar inclusive suas dificuldades sociais e de acessibilidade.

Neves (2006) esclarece que se faz importante ressaltar o conhecimento das remotas civilizações locais e o compreender das mesmas ou a sua integração ao meio em que viviam se torna nulo. O mesmo descreve que a Amazônia é ocupada há mais de 10.000 anos, em alguns casos por populações de milhares de pessoas. É de se esperar, portanto, que a floresta que hoje recobre muitos sítios arqueológicos tenha, além de uma história natural, também uma história cultural e identitária. Não se pode entender a história dos povos amazônicos sem considerar também as relações que os mesmos estabeleceram com a natureza e com eles mesmos.

Neste sentido, para a produção deste artigo, inspirado neste cenário amazônico, insurgiram questionamentos relacionados à ideia de identidade e reflexões que instigam o compreender dos processos identitários ribeirinho. Ressaltando-se a importância de pesquisas destinadas a este eixo temático e a contribuição do mesmo a nível científico. Para tanto, foram pontuados dois objetivos, o primeiro aborda a reflexão de conceitos sobre identidade e suas implicações. E, o segundo, enfatiza o ethos ribeirinho, discutindo as relações norteadas pelas questões identitárias no que concerne as formas com que o ribeirinho se expressa e se caracteriza enquanto ser amazônida. Assim, por meio de levantamento bibliográfico, construiu-se um aporte teórico, à luz das relações dos indivíduos que vivem e são parte de um universo tão singular que é a Amazônia, pois sua existência motiva a apreciação e a busca do compreender de sua poiésis identitária.

\section{ENTENDENDO O PROCESSO DA IDENTIDADE}

$\mathrm{Na}$ Amazônia de tantas paisagens e rios, biodiversidade e gentes, habitantes locais coexistindo numa espacialidade diversa, com recursos naturais, mas também com intempéries próprias da conjectura regional, insurge neste cenário o ser ribeirinho. A partir da construção de saberes e comportamentos, adquiridos ou abstraídos do meio em que se vive, o mesmo se mostra um indivíduo dinâmico. A constante plasticidade das sociedades amazônicas motiva adaptação da vivência em comunidade, da relação inerente aos seus valores, com seu entorno e com sua essência. Diante desse universo, torna-se instigante refletir acerca de como este ser se reconhece e dialoga com seu cotidiano.

A relação do homem e sociedade é uma questão que vai além de se viver em um grupo num determinado espaço. O homem amazônico constrói um território para além do físico, apreendendo suas crenças, mitos e superstições a um ethos característico. O mesmo conhece seu território e domina suas paisagens como se fossem ruas ou bairros, utilizando a natureza como referência, apropriando-se tanto física quanto simbolicamente do contexto que o cerca. 
Exaltando sua personalidade imbricada a seu cenário cotidiano, essa ação se torna diretamente intrínseca às suas características identitárias (FERREIRA; COSTA, 2015).

Para Wanzeler (2008) identidade está, de maneira estreita, relacionada ao reconhecimento, do contato dialógico com o outro, do reconhecer-se na identidade do semelhante, com o qual nos identificamos ou não. Este processo pode enveredar por meio subjetivo, individual, de construção de um imaginário coletivo, de forma ampla, abrangendo uma comunidade ou um país.

Neste sentindo, Silva (2011) contextualiza que o processo de identificação é "binário", ou seja, para que haja Eu é preciso que haja o Outro. Quando eu afirmo que sou, quando digo que sou, existe uma íntima relação entre identidade e diferença, elas estão relacionadas, há coexistência. Todavia a identidade não é fixa, cristalina, imutável, a mesma altera o modo de ver, sentir e pensar de uma sociedade. E isso irá ser volátil também quanto ao seu meio ambiente.

A identidade torna-se, então, questão de sobrevivência, ultrapassa a pura identificação com o outro, pois há necessidade de se estar em comunidade, estar junto para estar seguro. Havendo também a precisão de harmonização de convivência, seja em local estranho ou com pessoas desconhecidas, tal fluidez denota poder de mutação que o indivíduo possui. Essa face, que na verdade se transcreve como multifacetada, apresenta a capacidade que o ser humano possui de se enraizar ou não, que ao mesmo tempo em que se decodifica como pertencente a uma sociedade, também se desbrave enquanto ser que modifica a si mesmo.

Porquanto, Bauman (2005) articula que a consciência acerca da identidade não tem solidez de uma rocha, não é garantida para toda vida, é negociável. De que as decisões que o próprio indivíduo concretiza, os caminhos que percorre, a maneira como age e a determinação de se manter firme a tudo isso, são fatores cruciais para a formação de sua identidade. É preciso, para que transcorra esse processo de identificação, que o indivíduo se desprenda, muitas vezes, da ideia de pertencimento.

Oliveira (2013), elucida, quanto ao pensamento autônomo identitário, que é essencial a capacidade para pensar identidade sob o ponto de vista da construção, envolvendo aquisições, eliminações, adequações que, em sua ocorrência, evocam uma capacidade quase performática de, mesmo em processo, reter caracteres distintivos, de ser o mesmo sendo todo dia diferente, simples e complexo, estável e ao mesmo tempo em crise, imóvel e também em trânsito.

Logo, pode-se compreender que a identidade se perfaz na vivência do indivíduo quando há ação reflexa do mesmo com o outro, quando há diálogo estético e de ideias, onde não necessariamente esse processo precisa transcorrer, a princípio, verbalmente. Enfatizando o processo dialógico dele com ele mesmo e com o ambiente que o circunda. Precisa acontecer no poder de decisão de escolha, em que se assume fazer parte de um grupo e onde, ao mesmo tempo, as qualidades dessa decisão irão construir de forma constante o caráter desse ser humano.

Hall (2006), abordando concepções de identidade, enfatiza que uma das principais é a concepção sociológica em que apresenta a identidade pelo viés do interior e exterior, entre o mundo "pessoal" e o "público". Da projeção do que somos e da internalização dos valores sociais e culturais, alinham-se sentimentos subjetivos, a identidade "sutura" o sujeito à estrutura. O mesmo se torna cada vez mais fragmentado, formado por várias identidades e que experimenta um sistema de colapso no sentido de intensas mudanças estruturais e institucionais. Trazendo à tona o provisório, variável e problemático.

Todo esse complexo contexto volátil, muitas das vezes, explicita a constante construção e desconstrução do ser e de quanto o cenário que o mesmo está inserido influencia em seu ethos social e cultural. Logo, pode-se refletir acerca de contextos urbanos e rurais, e até mesmo na linha fronteiriça tão comum na contemporaneidade, reconhecida de forma singular como sendo áreas entre os centros urbanos e comunidades inseridas ao meio natural, 
ditas como ribeirinhas. Espaços que não só influenciam o seu modo de vida como de certa forma ditam e delineiam, por assim dizer, seus aspectos identitários, sua essência existencial.

Assim, Prado et al (2013) argumentam que a identidade pode ser definida como um conjunto de características pelas quais alguém pode ser reconhecido. Sob a ótica sociológica, a mesma é oriunda do caráter de uma pessoa ou de um grupo que se relaciona com que eles são e com o que tem sentido para eles. Ocorrendo uma mutação através dos tempos e das interações sociais do sujeito, ressaltando-se as várias etapas de sua vida e suas constantes negociações relacionais e ambientais.

Castro (2013) conjectura que nomear a identidade ribeirinha como sendo étnica, sobretudo contra sua própria compreensão, constitui uma violência simbólica das mais importantes quanto à formação da sociedade amazônica contemporânea. Violenta no sentido que foi uma identidade imposta, seja pela visão colonial, mercantilista ou até de cunho religioso. Sem deixar de citar a hesitação da prática científica, que apenas muito tardiamente começou a nomear ou ceder destaque literário a esse contexto.

É essencial se refletir que os povos tradicionais da Amazônia não viveram e não vivem isolados e nem estáticos no tempo e espaço. Há um estabelecimento de trocas, seja com as comunidades vizinhas ou entre um mesmo grupo que convive, são relações materiais e simbólicas. Indivíduos que permeiam entre rural e urbano, convivendo com mudanças constantes e, por isso mesmo, não se torna interessante ter uma visão cartesiana, visto que os dilemas sociais e culturais moldam seu modo de vida. Reforçando a ideia de que não estão estagnados e sua vida não se faz estritamente tradicional. Assim como os rios que cortam as florestas, ela se perfaz uma poiésis contínua.

\section{ETHOS RIBEIRINHO: UMA VISÃO MULTIFACETADA}

Amazônia, vasta terra, inexplorável, inóspita, com ricas e desconhecidas fauna e flora, com tribos "vivendo" sem Deus, sem lei, sem rei. Assim se revela o "início" da história de muitos povos, não só amazônicos, mas de toda uma nação. A confluência, ou mais adequadamente, a submissão e extermínio de tantos valores humanos e, claro, culturais, resume-se em sucessão de atrocidades impostas pelos primeiros colonizadores, pelo olhar do outro que vinha de fora, longe da realidade local. Questiona-se acerca do quanto de resquícios desses antepassados permaneceram e o quanto de sua essência identitária caracteriza até hoje o morador amazônico.

Diante de tantas possibilidades existenciais, encontram-se indivíduos moradores, agentes desse espaço. Ressalta-se o compreender de que forma ou formas esse indivíduo se reconhece, especialmente em suas nuances identitárias. De que maneira se compraz a sua identidade, que contornos carrega consigo e como vê o outro. Neste sentido, enfatiza-se reflexões acerca da identidade amazônica, pois as mesmas sempre permearam a essência humana do caboclo, mesmo diante de uma visão por vezes equivocada daqueles que nela aportavam. A Amazônia já vivenciava sua história, assim como o seu povo, este, inclusive, integrado e sujeito primordial em uma organização social desenvolvida em meio a um ambiente natural.

De acordo com Silva (2007), é preciso notar que a natureza é um componente a se considerar no que diz respeito à diversidade da Amazônia, principalmente quando se trata da compreensão dos modos de vida e das identidades das populações nela presentes, neste caso a ribeirinha. Existe um elo entre estas populações e o ecossistema. É nesta relação com a natureza que as populações tradicionais constroem todo seu modo de vida, a partir de um conhecimento empírico, que é transferido de pai para filho. Emerge-se o termo ribeirinho, que está intimamente integrado às populações que se instalaram na orla ou na extensão dos rios 
amazônicos, exaltando-se a sua localização, ou seja, aquele que reside nos rios. Termo que expressa uma associação geográfica e não uma identidade étnica.

Hall e Woodward (2014) explanam que a identidade se forma por meio de aspectos os quais as pessoas tomam suas posições e discursos que lhe são oferecidos, são conjugadas dimensão simbólica e social, natureza essencialista e não essencialista. Tais elementos explicam como as identidades são formadas e mantidas, sejam elas influenciadas pela biologia (aspecto essencialista) ou por meio de um processo fluido e mutante (não essencialista). Assim, surge a reflexão intrínseca sobre a constituição identitária do ribeirinho amazônico, os elementos que o perfazem e as formas que influenciam seu entorno, as dimensões que são conjugadas em suas vivências e práxis diárias enquanto sujeito.

Para Ferreira e Costa (2015) a Amazônia para muitos ainda é um profundo mistério, apesar de suas grandes riquezas e vasto território, com vivências de ciclos econômicos efêmeros, essa região desperta a necessidade de ser interpretada como questão nacional do ponto de vista, muitas vezes, estratégico. Vale ressaltar que a Amazônia presenciou o desenvolvimento das cidades, onde os protagonistas sociais de forma dinâmica foram e são agentes transformadores da realidade em que se encontram. Com o advento do sistema capitalista, agindo por sobre as relações sociais e do trabalho, suprimindo a forma de ganhar a vida e a convivência na dita sociedade moderna, um processo que se estenderia até os tempos atuais e de forma cada vez mais pragmática é o processo que causa a invisibilidade por sobre esses indivíduos.

A vida do homem ribeirinho amazônico é perpassada pela subjetividade e sincretismo, colocadas pela sua cultura e meio social. Há uma projeção, criação e recriação do seu imaginário, constituindo o mundo que o circunda. Mesmo sua vivência advinda de um tempo próprio, seja mítico ou cíclico, essas comunidades também vivem um tempo linear e contemporâneo. Ainda que venha de um processo de invisibilidade, é interessante desvelar suas identidades, suas ambiguidades e diferenciações sociais. Esta última responsável pelo entrave quanto à emancipação social e política. Torna-se pertinente refletir sobre de que forma se abordam categorias e atribuições deste indivíduo, quanto de sua diversidade influencia o seu olhar por sobre ele mesmo.

Rodrigues (2006) disserta que o processo de identidade do homem amazônico se distingue em uma vivência nominal, ou seja, como são nomeados ou como se reconhecem enquanto fazendo parte de um grupo. Parte de uma ideia de categorização social de difícil categorização, de um objeto difícil de ser objetificado - a identidade (ou não - identidade) do caboclo amazônico. No caso específico da categoria caboclo, uma categoria de atribuição pelos outros e não de auto - atribuição, elemento de acusação e não de reconhecimento de direitos e prerrogativas, logo se questiona a possibilidade se ela existe de fato. Isto é decorrente, justamente, da invisibilidade social, proveniente de uma ação que enfatiza a diferença, estigmatizando grupos ou pessoas, negando ou limitando acesso às oportunidades na sociedade mais ampla.

Para Neto e Furtado (2015) o termo ribeirinho busca identificar um perfil sociocultural de grupos caboclos que se estabeleceram às margens dos rios, dialogando com o espaço dinâmico das relações de sociabilidade e culturais dentro das especificidades desse mesmo espaço. Configurando seu comportamento, hábitos alimentícios, crenças etc. Não se moldando uma tipologia do caboclo amazônico, mas sim de uma expressão cultural que envolve particularidades inerentes a essa definição. Esse conceito pode estar atrelado mais ao caráter da relação estabelecida com o rio, sendo esse meio natural o principal definidor dos aportes culturais. $\mathrm{O}$ ribeirinho pode ser um caboclo desde que haja uma conexão com o meio rural.

Neste sentido, ao longo dos tempos, o habitante amazônico recebe sua identidade nominal, pode-se assim dizer, por meio de diversos termos, citados justamente em registros de 
pesquisadores e historiadores. Nomes que autenticam de alguma maneira o morador local, dentre eles ribeirinhos, povos da floresta, povos tradicionais, caboclos, todos estes exaltando a expressão da relação social. Então, pondera-se sobre a riqueza dessas relações, sobre todo esse emaranhado de saberes e culturas de quem vive por meio do olhar do outro, de aceitação e até de negação, ou seja, contextualiza-se sua identidade.

Freitas (2009) esclarece que as populações contemporâneas da Amazônia são compostas por grupos sociais urbanos e rurais, de sociedades e comunidades indígenas de várias articulações histórico-social, de grupos isolados com arranjos próprios de sobrevivência e de migrantes provenientes de exploração econômica. Isto acarreta consequências desiguais de desenvolvimento das formas de exploração econômica capitalista. O termo exclusão, na Amazônia, pode ser expresso em relação à renda, educação, condições quanto à população infantil, condições habitacionais, acesso à saúde básica e força de trabalho. Elementos que, juntamente com as feições demográficas e dificuldade de acesso, culminam por implicar, de forma muito peculiar, na qualidade de vida dos povos ribeirinhos.

Reflete-se, diante desse processo contínuo, que a identidade amazônica é fomentada pelas diferenças coletivas, condições de acesso, heranças populares ou genéticas, culturais, pertencimento a linhas geográficas, raça, etnia, descendência indígena ou existência cabocla. Assim, a identidade se torna um processo abstrato complexo, pois ao mesmo tempo em que o habitante amazônico constrói sua vivência a partir da essência coletiva, também possui o senso de alteridade. Caboclo se torna uma categoria de alteridade, que fala sempre de um outro, enfatizando uma categoria de representação.

Destarte Adams, Murrieta e Neves (2006) pontuam que as sociedades caboclas são paradoxais, ambivalentes e difíceis de serem categorizadas, pois são regionais, mas cosmopolitas, diversas, mas peculiares, tradicionais, mas modernas. Isso pela influência de dois cenários, o cultural e o econômico, que pela não assimilação de novas oportunidades dessas comunidades, adequações política - econômica, precisam contar com sua própria resiliência para continuar existindo, em meio a tantas crises. Como consequência dessa diversidade e complexidade, percebe-se uma dificuldade em se enquadrar justamente uma unidade identitária, pois a identidade cabocla ou ribeirinha está muito mais próxima dos aspectos externos (transformações econômicas globais) do que nas continuidades locais (como em relação às populações indígenas).

Observa-se relativa dificuldade para autodefinição do morador amazônico, pois ainda quando o mesmo se insere em um grupo e recebe denominação, ocorre que, circunstancialmente, pode não se sentir representado ou até mesmo inferiorizado. Torna-se importante ressaltar que esse se sentir inferior pode advir inclusive do não conhecimento da própria cultura que pertence. Entretanto, o processo inverso também ocorre, a aceitação e entendimento do fazer parte deste grupo, do ser caboclo, tem se tornado mais perceptível.

De um modo geral, o ser amazônico no decorrer de sua trajetória histórica, em face de outras sociedades, teve impossibilidade, não de constituir sua própria identidade amazônica, mas, de demonstrar de fato como era e é constituída esta identidade. Povos inseridos neste universo natural, denominado com o tempo por "Amazônia", possuem características distintas de qualquer outro lugar do mundo. Ser amazônida vai além de uma localização espacial, implica na reinvenção de si mesmo e aborda as alteridades amazônicas.

Neste sentido, Silva (2017) corrobora que existem três visões por sobre os ribeirinhos da Amazônia. A primeira delas é que há uma visão naturalista que ignora a identidade amazônida, por se ter um olhar para essa região somente como fonte de recursos naturais e como conjunto de ecossistemas. Isso acarreta o reforço da inexistência e invisibilidade das populações tradicionais, anulando sua historicidade e cultura dos atores sociais afirmadas a partir da diversidade territorial de grupos defasados na sua diversidade social. A segunda se perfaz por meio de um olhar idílico, que vislumbra a rica diversidade cultural dos ribeirinhos 
apenas como algo natural e não como algo que foi produzido socialmente no decorrer da história. Engendrado pelo desenvolvimento verticalizado na Amazônia.

A terceira visão é a de que existe um olhar moderno que resulta em conceitos infundados de tais populações. Esta é centralizada em um conjunto de representações e simbologias fundamentadas no preconceito, onde as populações ribeirinhas são tidas como atrasadas e improdutivas em relação aos espaços que são modernos. As comunidades são vistas como rústicas e primitivas, evidenciando-se assim atribuição do estereótipo do caboclo. Logo, são tratadas por alguns literários com racismo, sendo denominados apenas como ocupantes.

Entende- se que a identidade ribeirinha é imbricada ao espaço territorial, no sentido que são construídas simbologias enquanto sociedade que pertence aquele espaço geográfico. No entanto, é necessário se compreender que nem toda identidade constrói territórios e viceversa, pois existe o aspecto espaço-temporal. Que o território se faz sim um elemento contundente, mas que precisa de outros aspectos que também irão estabelecer um sistema que constrói determinada sociedade, seja cultural ou socialmente.

Assim sendo, o caboclo em sua prática do dia a dia será influenciado pelas características sazonais dos rios, por exemplo. Ao mesmo tempo em que informações da mídia ou mudanças econômicas e políticas também irão contribuir para sua mudança ou adequação enquanto ser social. O rio e a floresta são vias, "ruas" de locomoção e fonte de recursos naturais, contudo se expressam como elementos que influenciam os povos ribeirinhos também quanto às suas crenças e mitos. Logo, ao mesmo tempo em que conta suas histórias e repassa seus conhecimentos quanto ao modo de pescar, roçar ou que caminhos traçar nos rios, também incorpora formas de se comunicar utilizando a tecnologia. Isso ao mesmo tempo que beneficia quanto à sua inserção social, muitas das vezes, também vai descaracterizando algumas nuances elementares.

Para Silva (2017) a identidade na Amazônia está articulada à ideia de pertencimento, aos laços de dependência e consideração a um grupo ou comunidade, expressando uma construção histórica relacional e também de contraste, justamente por haver conflitos entre identidades que atribuem o auto - reconhecimento e alteridade. E é nessa complexa rede relacional que é suscitada a consciência de pertencimento. É nessa relação entre comando e apropriação em meio ao vivido e concebido que se constitui o pertencimento sócioespacial.

Por outro lado, Rodrigues (2006) disserta que o termo caboclo não se refere a um grupo social e nem corresponde a um grupo étnico. Alguns habitantes das áreas ribeirinhas se definem como agricultores; também não são associados a um movimento político; por isso talvez deva desistir do uso da palavra caboclo, especialmente se pretender falar sobre as identidades rurais da Amazônia contemporânea. Posto que a identidade cabocla não existe de fato, é uma "representação", não há uma afirmação de ser caboclo, mas uma aceitação contextual. Talvez por se pensar esse fenômeno como recusa do termo em função de um sentido pejorativo no contexto onde é produzido, mas também pela afirmação que esses indivíduos não fazem parte de uma categoria "branca" que os rotula e discrimina.

Fraxe, Witkoski e Miguez (2009) explanam que os grupos sociais que habitam a Amazônia possuem uma singularidade quanto à transmissão de costumes e práticas, que ainda são feitos de geração em geração, ainda que não se tenha um reconhecimento político de suas existências. O fluxo histórico e continuidades e descontinuidades formaram rotas, hábitos e identidades, onde nesses territórios emergiram diferentes tipos sociais, que para sobreviverem nas adversidades se reinventaram em meio ao ecossistema. A alteração na composição étnica fez surgir frutos da mistura racial, em que o estilo de vida ainda é imbuído aos ancestrais mais remotos - ameríndios da várzea e terra firme.

Rodrigues (2006) disserta que a categoria caboclo se torna uma problemática teórica e ética, assim como política, uma identidade reificada pela negação, como um indivíduo que 
está fora do contexto da modernidade contemporânea. No entanto, é também aquele que, por vezes, não tem a consciência de si e que é expresso por representações estereotipadas construídas por outro e mesmo por meio de uma "dupla consciência".

Persiste uma dicotomia em manter a palavra caboclo, pois, por um lado, manter este termo pode demonstrar um desconhecimento das formas como eles mesmos se representam. Tomando como ponto de partida que a identidade cabocla é uma representação, no sentido de construção através dos quais os sujeitos são rotulados, há um outro ponto em que "matar" o termo caboclo enquanto conceito seria negar que não existe uma singularidade ou diferença que se construiu historicamente.

Para Rodrigues (2006), ocorre um processo inverso à ideia de identidade nacional, pois o mesmo não se integrou à sociedade brasileira em paralelo ao processo de anulação dessa (não) identidade. Neste sentido surge a questão da invisibilidade, acarretando a isso uma falta de memória, sua história silenciada e ausências quanto às políticas públicas e assistências sociais de forma ampla e efetiva.

Destarte, nos últimos anos, nos discursos que se referem à biodiversidade amazônica, o caboclo ribeirinho é visto como guardião da floresta. Assim é tido como detentor dos saberes da região, herdeiro dos seus ancestrais indígenas, originário do lugar e ser totalmente adaptado ao ecossistema local. Na mídia são abordados também termos como: povos da floresta e povos tradicionais. Sendo assim, a identidade dos caboclos é uma contraidentidade, pois muitas vezes foi visto como termo depreciativo para indicar pessoas que não se sabiam com a mesma identidade, haja vista a longa tradição segregatória que o envolveu.

Para Castro (2013) a concomitância de raízes indígenas e não indígenas das sociedades caboclas a tornaram, ao olhar da antropologia, sociedades "não autênticas". Contudo não dizem tudo sobre a invisibilidade dos caboclos. Contextualizam razões científicas, mas, não sendo essas razões, necessariamente, ou mesmo normalmente, apropriadas pela prática social dos agentes que a nomeiam, elas não esclarecem o silêncio dos caboclos a respeito deles mesmos. Assim, não se considera o caboclo como uma categoria biótica, ou um cidadão "mestiço", pois há uma condição antrópica, social e subjetivamente conformada por representações culturais denegativas.

Ponderações acerca da identidade ribeirinha cabocla permeia um contínuo debate enquanto sua representatividade social, há uma reflexão justamente sobre a dimensão quanto sua visibilidade e invisibilidade. A que se levar em consideração se ocorre um processo de identidade forjada, seja de forma consciente ou não. Para isso, parte dessa ação vem da compreensão do que se compraz esses grupos e levar em consideração a presença do contraditório em seu contexto, seja culturalmente ou nas suas outras manifestações. Leva-se em consideração seus territórios e o pensar nesse individuo de forma não romantizada.

Fraxe, Witkoski e Miguez (2009) dissertam que houve momentos que certas instituições eram fundamentais para garantir costumes e tradições, porém que a nível contemporâneo, tais instituições também estão inseridas no processo de descontinuidade e reformulação. Igreja e família, por exemplo, assumiram um papel fundamental nas comunidades ribeirinhas, mas elas também, mesmo que ainda garantam relações de troca, sejam materiais ou imateriais, estão atualmente suscetíveis às novas formas de se relacionar. Estão se transformando significativamente, sendo contagiadas por novos hábitos e interesses da sociedade atual.

Fraxe, Witkoski e Miguez (2009) explanam que é preciso compreender as consequências da modernidade na construção e reconstrução de uma suposta identidade amazônida. Parte-se da observação que o homem amazônico não está estagnado, ainda que seja mantida suas práxis diárias tradicionais, a todo momento recebe influências tanto urbana, industriais e tecnológicas. Há uma descontinuidade presente na realidade ribeirinha. 
Para Rodrigues (2006) o ribeirinho é tido também como alguém que é reconhecido por incorporar uma cultura de resistência, utilizando suas fronteiras políticas e éticas. Posto que são sobreviventes em um processo aniquilador, mas que não os extinguiu por completo. Sobreviventes que estão entre culturas, em meio à modernidade, vislumbrando a construção de novos sujeitos, no entrelugares que permite seu fazer e refazer constantemente.

\section{RESULTADOS E DISCUSSÃO}

Torna-se necessário assimilar o processo contínuo de ressignificação e reconstrução do indivíduo enquanto ser social, diante especialmente de suas múltiplas identidades. Essas vias de transformação se torna pragmática diante do acesso às informações e tecnologias, causam fusões e são internalizadas ou não. Por meio de decisões, escolhas e interesses vai se costurando a identidade ribeirinha, deixando no passado a ideia do homem amazônida preconcebido ou romantizado. Neste sentido, a visibilidade para os povos ribeirinhos tem sua força no momento em que são reconhecidas enquanto ao seu caráter diverso e singular, construindo um entendimento que transpasse os discursos ecológicos, muitas vezes, aquém da realidade. Trazendo para o protagonismo o sujeito caboclo enquanto ser primordial na sua formação política e de suas vertentes identitárias.

Historicamente é notável que aos povos amazônicos, especialmente, os indígenas, não foi dado o direito de prosseguir claramente com seus costumes e crenças, pois o mesmo foi visto pelo colonizador apenas como sendo uma peça neste universo, ou seja, muito de seus valores foram ignorados, seu pensamento e o modo como interagia com sua terra não foi levado em consideração. Contudo, resquícios dessa cultura, com o passar dos tempos, continuaram a ser incorporados como expressões amazônicas, hábitos e conhecimentos, oriundos de sua vivência ribeirinha, permeiam a sua forma de vida, mesmo diante de mudanças sociais, políticas e econômicas. Tais elementos implicam no caráter formador dos que habitam os rios e florestas, especialmente quanto ao seu caráter identitário.

\section{CONSIDERAÇÕES FINAIS}

É evidente que o ser ribeirinho possui importantes traços que o caracterizam enquanto indivíduo que permanece morador e protagonista de um território que, ao mesmo tempo é cobiçado por seus recursos naturais, mas que também continua a ser um grande desafio para aqueles que buscam, por exemplo, compreender a sua essência. Neste sentido, entende-se que há importantes apontamentos quanto às formas que o caboclo ou ribeirinho perfaz sua identidade amazônida. Um ponto elementar é que residir neste cenário natural caracteriza o ribeirinho não exatamente como uma identidade étnica, mas expressa mais um caráter de uma associação geográfica. Ou seja, seu ser e fazer diário está intimamente ligado aos seus hábitos e formas com que lida com sua comunidade e com seu entorno. Logo, não tendo que ser reconhecido exatamente como uma categoria étnica. Assim, não se define uma tipologia cabocla, pois o que se vislumbra é sua expressão cultural e social, que são inerentes a essa definição.

Visões sobre o ribeirinho e povos tradicionais da Amazônia, de um modo geral, muitas vezes são inadequadas e fomentam o romantismo, no sentido em que postulam análises que não representam a realidade dessas comunidades. Uma delas é que ainda se aborda a visão naturalista, onde o que importa são os recursos naturais e ecossistemas, reforçando que o caboclo não possui autonomia e é desconsiderada sua história territorial. Corrobora para tanto também o olhar idílico, que ignora as diferenças e inclusive a própria identidade, processo que se baseia na desigualdade e exclusão social. Neste cenário é importante ainda citar a ideia 
equivocada de que o ribeirinho é caracterizado como sendo improdutivo e fora do processo de modernidade.

A realidade social do ribeirinho é sobretudo desafiadora, pois sejam comunidades próximas ou mais distantes de áreas urbanas, as mesmas perpassam por contextos semelhantes, os direitos e acesso à serviços essenciais são ainda muito aquém da sua real necessidade. Esse contexto também vai agir diretamente no seu ethos identitário, pois essa lacuna ocasiona o processo da invisibilidade. É essencial que o mesmo seja inserido nas mudanças históricas, sociais, políticas e culturais, visto que assim é o dinamismo nas sociedades contemporâneas. Com sua participação consciente em tomadas de decisão é possibilitado sua emancipação, deixando para o passado os resíduos coloniais, pois assim sua voz ecoará com propriedade sua vivência e relação com a natureza, mas sobretudo desvelando seu caráter dialógico identitário. Outro caráter imprescindível, ainda resquício da questão da invisibilidade, é o da autodefinição, de se auto denominar ribeirinho.

A aceitação ou não advém de questionamentos provenientes do discurso feito pelo outro, que acarreta a diferenciação, feita de forma preconceituosa por outros povos. A identidade nominal, muitas das vezes, foi feita pelo olhar que enfatiza justamente a diferença e que culmina na inferioridade. No entanto, o que deve ser considerado é que a identidade do ribeirinho se constrói exatamente no jogo da diferença. Sua essência é volátil, é uma fronteira em movimento, pois possui um senso de resiliência. Diante de tantas transformações decorrentes às mudanças globais, o mesmo mantém sua vivência no coletivo, mas também no senso de alteridade. Adaptando-se permanentemente às circunstâncias que a natureza também apresenta.

Assim, pode-se entender que os reflexos do conceito de identidade na vivência nativa do ser amazônida permeia à luz de aspectos como independente da forma ou termo que ele é nomeado, o homem ribeirinho integra seu comportamento à sua realidade e que, até por lacunas históricas quanto à sua origem, ele se encontra na diferença. Outro achado identitário é sua capacidade de relação tanto social quanto ao entorno natural que o mesmo está inserido, em que busca viver em grupos, e onde o conceito de identidade demonstra semelhanças vivenciais entre o que estão neste grupo. Neste sentido, por meio destas relações realiza contínua construção de sua essência identitária. É imprescindível desmistificar pressupostos generalistas que foram construídas entorno das comunidades ribeirinhas, e compreender de fato que as mesmas são edificadas pela diversidade de seu aspecto sociocultural e sua poiésis identitária.

\section{REFERÊNCIAS}

ADAMS, Cristina; MURRIETA, Rui; NEVES, Walter. (Orgs). Sociedades caboclas amazônicas: Modernidade e invisibilidade. 2006. São Paulo: FAPESP, Ed. Annablume.

BAUMAN, Zygmunt. Identidade. Rio de Janeiro: J.Z.E., 2005.

CASTRO, Fábio Fonseca. A identidade denegada. Discutindo as representações e a autorepresentação dos caboclos da Amazônia. Da Amazônia. Revista de Antropologia 56 (2), 431-75. 2013.

FERREIRA, Geone Angioli; COSTA, Noélio Martins. Razões da invisibilidade na Amazônia profunda. In: III CONGRESSO PAN - AMAZÔNICO DE HISTÓRIA ORAL e VIII SEMANA DE HISTÓRIA DO CESP-UEA, 2015, Parintins. Anais [...]. Parintins: CESP, 2015. Disponível em: 
https://www.norte2015.historiaoral.org.br/resources/anais/12/1436366752_ARQUIVO_RAZ OESDAINVISIBILDADENAAMAZONIAPROFUNDA.pdfAcesso em: 02 jul. 2020.

FRAXE, Theresinha de Jesus; WITKOSKY, Antônio Carlos; MIGUEZ, Sâmia Feitosa. O ser da Amazônia: identidade e invisibilidade. Ciência e cultura. v. 61, p. 30-32, 2009.

FREITAS, Marilene Corrêa da Silva. Os Amazônidas contam sua história: territórios, povos e populações. Manaus: Editora da Universidade Federal do Amazonas, 2009.

HALL, Stuart. A identidade cultural na pós-modernidade. Rio de Janeiro: D. P. \& A., 2006.

HALL, Stuart; WOODWARD, Kathryn. Identidade e diferença. Rio de Janeiro: Vozes, 2014.

NETO, Francisco Rente; FURTADO, Lourdes Gonçalves. A ribeirinidade amazônica: algumas reflexões. Cadernos de campo, São Paulo, n. 24, p. 158-182, 2015.

NEVES, Eduardo Góes. Arqueologia da Amazônia. Rio de Janeiro: Jorge Zahar, 2006.

OLIVEIRA, Alexandre Santos. Identidade cultural e ensino do design no Amazonas. 2013. Tese (Doutorado em Design) - Programa de Pós-graduação em Design do Departamento de Artes \& Design, Pontifícia Universidade Católica do Rio de Janeiro, Rio de Janeiro, 2013.

PRADO, Alcindo Ferreira et al. Ser professor na contemporaneidade: desafios da profissão. Disponível em: https://www.inesul.edu.br/revista/arquivos. Acesso em: 16 mar. 2020.

RODRIGUES, Carmen Isabel. Caboclos na Amazônia: a identidade na diferença. Novos Cadernos NAEA. V.9, n. 1, p. 119-130, jun. 2006, ISSN 1516-6481.

SILVA, Auliam. Identidade, literatura e alteridade na Amazônia do relato de um certo oriente. Pará: UFPA - Belém, 2011.

SILVA, Ieda Rodrigues. Modo de vida ribeirinho: construção da identidade amazônica. VIII Congresso Luso-Brasileiro de Ciências Sociais; Coimbra, 2017.

SILVA, Orlando Sampaio. Eduardo Galvão: Índios e caboclos. São Paulo: Annablume, 2007.

WANZELER, Rodrigo de Souza. Heterogeneidade amazônica: cultura(s) e identidade(s) em Candunga, de Bruno Menezes. In: CONGRESSO INTERNACIONAL DA ABRALIC: TESSITURAS, INTERAÇÕES, CONVERGÊNCIAS, 2008, São Paulo. Anais [...]. São Paulo: ABRALIC; USP, 2008. Disponível em: www.abralic.org.br. Acesso em: 30 mar. 2020. 